ISSN : $0854-5405$

c-ISSN : $2622-8114$
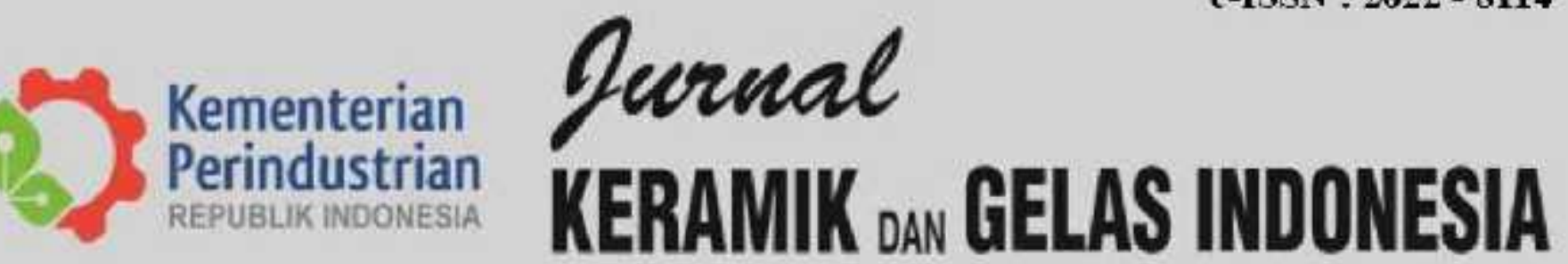

JOURNAL OF THE INDONESIA N CERAMICS AND GLASS

Vol. 29 No.2 Desember 2020
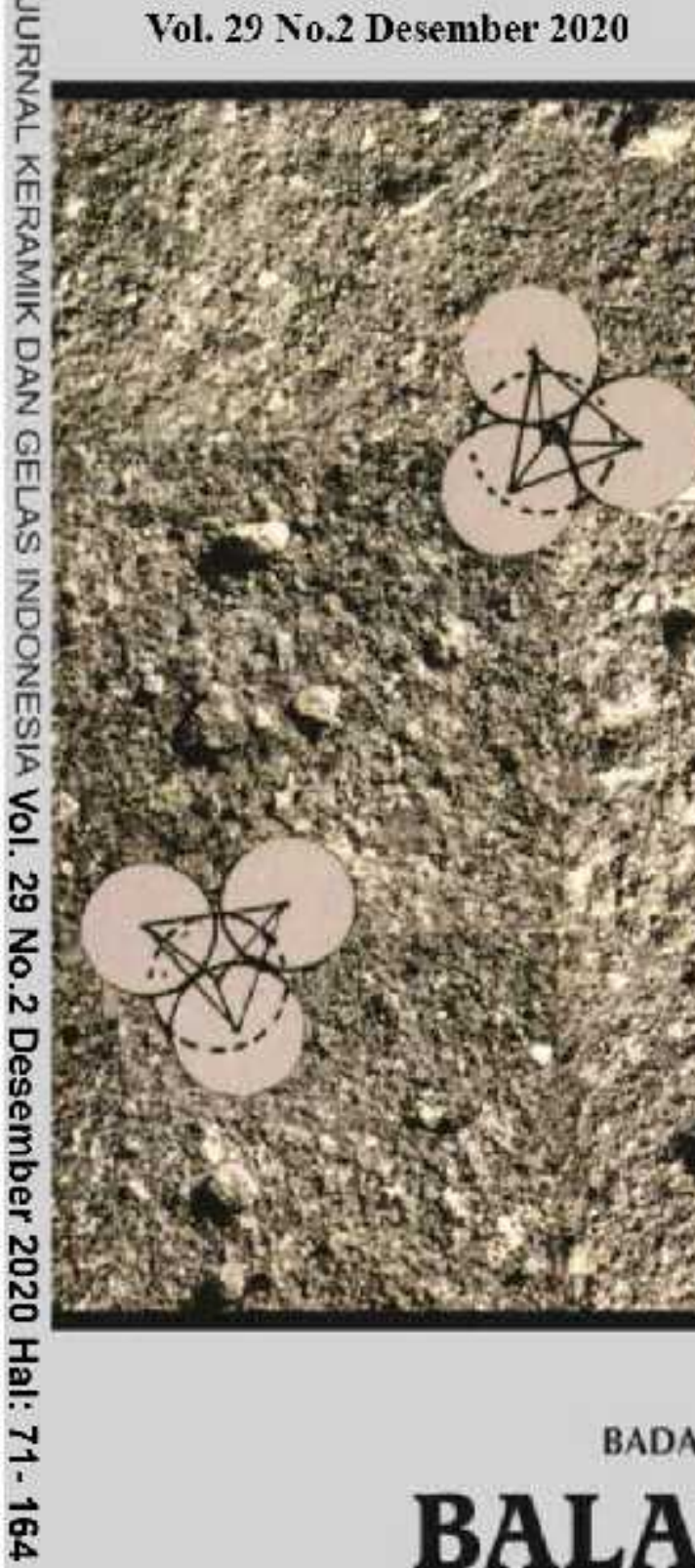

3.

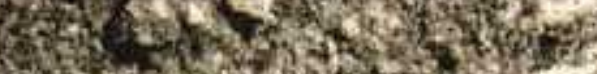
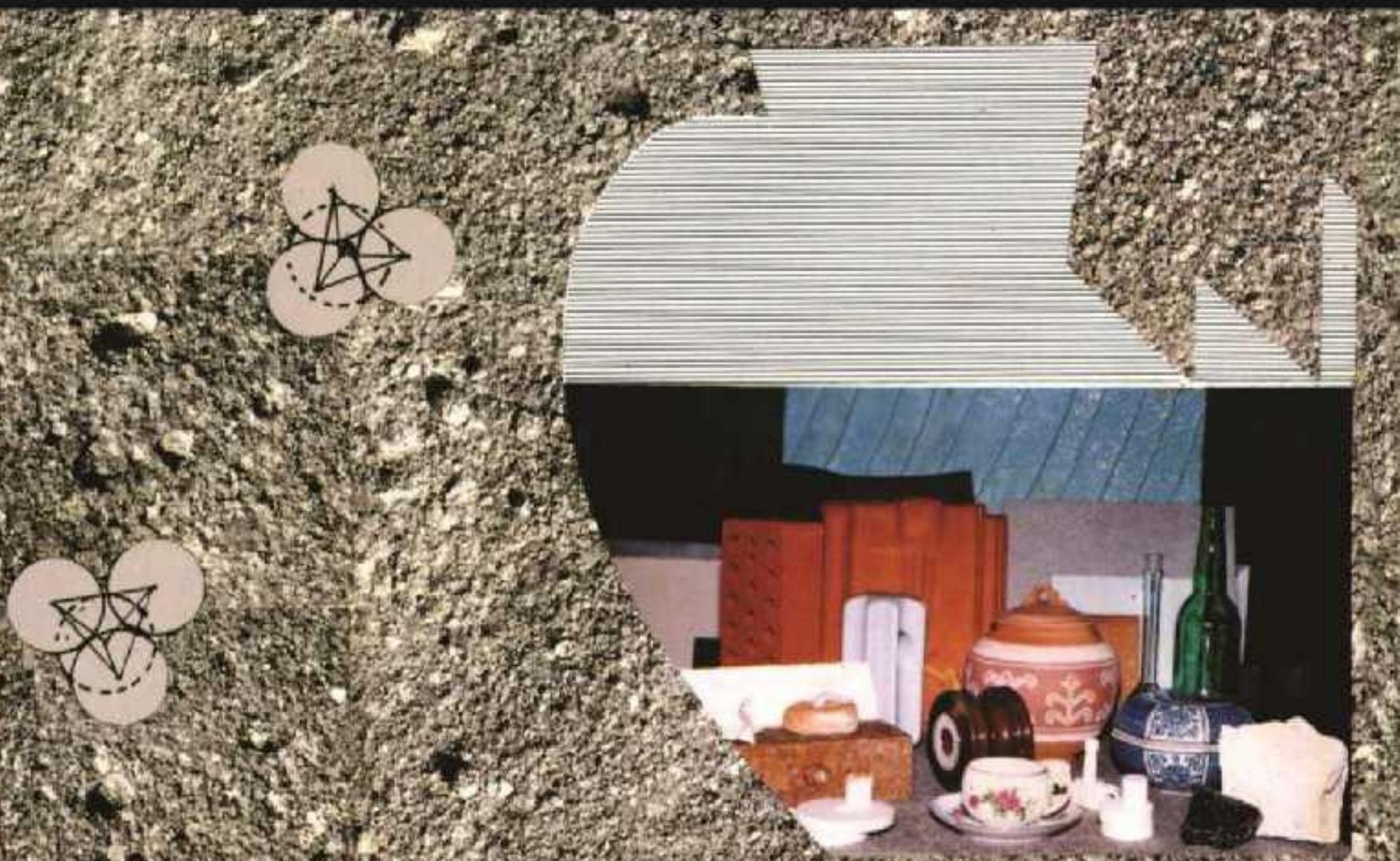

16:

KEMENTERIAN PERINDUSTRIAN

BADAN PENELITIAN DAN PENGEMBANGAN INDUSTRI

BALAI BESAR KERAMIK

\begin{tabular}{|c|c|c|c|c|c|}
\hline JKGI & Vol. 29 & No.2 & Hal. 71-164 & $\begin{array}{c}\text { Bandung } \\
\text { Desember 2020 }\end{array}$ & $\begin{array}{c}\text { ISSN:0854-5405 } \\
\text { e-ISSN:2622-8114 }\end{array}$ \\
\hline
\end{tabular}

'Tcrakreditasi No : 34/E/KP' I/2018 


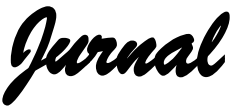

\section{KERAMIK DAN GELAS INDONESIA}

\author{
JOURNAL OF THE INDONESIAN CERAMICS AND GLASS
}

\section{Vol. 29 No. 2 Desember 2020}

Jurnal Keramik dan Gelas Indonesia adalah majalah ilmiah yang diterbitkan dua kali dalam setahun untuk menyebarluaskan hasil-hasil penelitian dan pengembangan serta ulasan ilmiah tentang keramik dan gelas kepada lembaga penelitian dan pengembangan, ilmuwan, dan peminat lainnya. Tulisan dalam Jurnal Keramik dan Gelas Indonesia dapat dikutip dengan menyebutkan sumbernya.

\section{Penanggung Jawab}

Kepala Balai Besar Keramik

\section{Tim Penilai Kelayakan/Mitra Bestari}

Prof. Ir. Bambang Sunendar Purwasasmita, M.Eng., Ph.D

Prof. Dr. Eng. Mikrajuddin Abdullah, M.Si

Dr. Ir. Aristianto Muslim M. Barus, MScE

Dr. Handoko Setyo Kuncoro, ST, MT, M.Eng, Ph.D

Dr. Eneng Maryani, S.Si, MT

Dr. Dani Gustaman Syarif, M.Eng

Dr. Diana Rakhmawaty E, M.Si

Dra. Sri Cicih Kurniasih, M.Si

Ir. Subari

Ir. Hernawan, MT

Dra. Naniek Sulistarihani, M.S

Editor

Dr. Rifki Septawendar, S.Si, MT

\section{Section Editor}

Ria Julyana Manullang, MT

Naili Sofiyaningsih, ST, M.Si

Maulid Purnawan, S.Si

Dadan Sumardan, S.Sn., M.Ds

\author{
Alamat \\ Balai Besar Keramik \\ Jl. Ahmad Yani No. 392 Bandung 40272
}

Telp: (022) 7206221, 7207115, 7206296, Fax: (022) 7205322

e-mail: keramik@bbk.go.id 


\title{
$\ldots$
}

\section{KERAMIK DAN GELAS INDONESIA}

\author{
JOURNAL OF THE INDONESIAN CERAMICS AND GLASS
}

Vol. 29 No. 2 Desember 2020

\section{DAFTAR ISI}

1. Pemanfaatan Arang Sekam Padi Sebagai Sumber Silika Pada Sintesis $\quad$ 71-81 Forsterit Dalam Medium Udara

The Utilization of Rice Husk Charcoal as a Source of Carbon and Silica in The Synthesis of Forsterite/Carbon Composite in Air Medium Solihudin, Haryono

2. Sintesis Dikalsiumfosfat Anhidrat Untuk Prekursor Bahan Keramik Apatit $82-91$ Dari Bahan Alam

Synthesis of Anhydrous Dicalcium Phosphate for Precursor of Natural Ceramic Apatite Material

M. Syaifun Nizar, Rizky Berliana W, Kristanto Wahyudi

3. Modifikasi Pembentukan Mineral Monetit Dengan Kontrol Laju 92-100 Penambahan Asam Fosfat

Modification of Monetite Formation by Controlling of Phosphoric Acid Addition

Herlina Damayanti, Karlina Noordiningsih, Kristanto Wahyudi

4. Sintesis $\beta$-TCP Dengan Metode Presipitasi Basah Dari Bahan Kapur Alam Synthesis of $\beta$-TCP by Wet Precipitation Method from Natural Lime

Ayu Ratnasari, Naili Sofiyaningsih, Muhammad Syaifun Nizar, Hernawan

5. Pembuatan Filter Keramik Makropori Melalui Metode Replika Templat Poliuretan: Karakterisasi Dan Uji Coba Filtrasi Air Detergen

Macroporous Ceramic Filter through Polyurethane Template Replication Method : Characterization and Detergent Wastewater Filtration Trials Riska Siti Maspupah, Eneng Maryani, Eko Prabowo Hadisantoso

6. Sintesis Dan Karakterisasi Lempung Terpilar $\mathrm{Al}_{2} \mathrm{O}_{3}$ Dan Termodifikasi Cetyl 123-138 Piridinium Chloride Synthesis and Characterization of Cetyl Piridinium Chloride Modified and $\mathrm{Al}_{2} \mathrm{O}_{3}$ Pillared Clay

Ferry Arifiadi, Irna Rosmayanti, Herlina Damayanti, Hernawan, Kristanto Wahyudi

7. Cullet Dalam Ekonomi Sirkular Industri Kaca Cullet In The Circular Economy Of The Glass Industry Maulid Purnawan, Ria Julyana Manullang, Kristanto Wahyudi

8. Kajian Teknoekonomi Kaolin Belitung Sebagai Bahan Substitusi Impor Pada Produksi Fiber Cement Board Technoeconomic Study of Belitung Kaolin as Import Substitution Material in Fiber Cement Board Production Nurhidayati, Faiza Elisa Hasfianti, Kristanto Wahyudi 


\section{KATA PENGANTAR}

Jurnal Keramik dan Gelas Indonesia Vol.29 No.2 Desember 2020 ini menyajikan 8 (delapan) makalah yang ditulis oleh peneliti Balai Besar Keramik dan instansi litbang lainnya. Makalah-makalah tersebut membahas tentang pemanfaatan arang sekam padi sebagai sumber silika pada sintesis forsterit dalam medium udara, sintesis dikalsiumfosfat anhidrat untuk prekursor bahan keramik apatit, modifikasi pembentukan mineral monetit dengan kontrol laju penambahan asam fosfat, sintesis $\beta$-TCP dengan metode presipitasi basah, pembuatan filter keramik makropori melalui metode replika templat poliuretan, sintesis dan karakterisasi lempung terpilar $\mathrm{Al}_{2} \mathrm{O}_{3}$ dan termodifikasi cetyl piridinium chloride, cullet dalam ekonomi sirkular industri kaca, serta kajian teknoekonomi kaolin belitung sebagai bahan substitusi impor pada produksi fiber cement board.

Pada makalah pertama telah dilakukan penelitian arang sekam padi sebagai sumber silika dan karbon untuk bahan baku pembuatan forsterit maupun komposit forsterit/karbon. Hasil penelitian menunjukkan bahwa suhu kalsinasi dalam medium udara mempengaruhi proses pembentukan ikatan-ikatan kimia pada struktur forsterit.

Pada makalah kedua dilakukan penelitian penyiapan bahan dikalsium fosfat dari bahan baku mineral kapur alam dengan metode yang mudah diterapkan untuk skala produksi industri. Dari hasil penelitian diperoleh hasil dengan variasi kadar kalsium bahan DCPA dapat dijadikan sebagai prekursor apatit lain.

Pada makalah ketiga berhasil menyintesis mineral monetit dengan menggunakan metode presipitasi basah yang dimodifikasi dengan mengontrol laju penambahan asam fosfat ke dalam kalsium hidroksida. Kondisi optimal pembentukan mineral monetit telah diperoleh. Hasil penelitian ini memberikan peluang untuk dilanjutkannya penelitian ke tahap aplikasi mineral monetit pada bidang medis, terutama dalam rekayasa jaringan tulang.

Pada makalah keempat dipaparkan mengenai sintesis bahan $\beta$-trikalsium fosfat dengan bahan baku kapur alam dan asam fosfat. Hasil penelitian berupa serbuk $\beta$-TCP yang terbentuk pada suhu $800^{\circ} \mathrm{C}$.

Pada makalah kelima telah dilakukan pembuatan filter keramik makropori melalui metode replika templat poliuretan. Hasi penelitian berupa filter yang termasuk makropori dengan morfologi sangat porous dan memiliki interkoneksi atau channel antar pori.

Pada makalah keenam telah dilakukan sintesis lempung terpilar $\mathrm{Al}_{2} \mathrm{O}_{3}$ dengan metode interkalasi oleh surfaktan Cetyl Piridinium Chloride (CPC) dengan variasi persen berat dan dilanjutkan dengan pilarisasi oleh aluminium poliokso. Hasil yang diperoleh adalah bentonit yang dimodifikasi CPC dan aluminium poliokso mempunyai karakteristik jarak basal dan luas permukaan yang lebih tinggi dibandingkan dengan bentonit alam.

Pada makalah ketujuh dipaparkan tentang cullet dalam ekonomi sirkular industri kaca. Dalam makalah ini, telah disusun model ekonomi sirkular pada industri kaca yang menitikberatkan pada pengelolaan cullet melalui proses reduce, reuse, recycle dan regenerative menjadi cullet sebagai bahan baku kaca. 
Makalah kedepalan menyajikan paparan kajian teknoekonomi kaolin belitung sebagai bahan substitusi impor pada produksi fiber cement board. Berdasarkan kajian teknoekonomi berbasis NPV, analisa usaha yang dilakukan dengan kaolin Belitung sebagai bahan substitusi impor menunjukkan bahwa usaha layak dikembangkan dengan nilai NPV sebesar 86.071.631.216,30 untuk harga jual papan semen Rp. 55.000 per lembar.

Hasil penelitian dan kajian di atas diharapkan dapat menyumbangkan kemajuan teknologi keramik di Indonesia, sehingga tidak terlalu tertinggal dengan kemajuan teknologi keramik di negara lain.

Redaksi 